\title{
A STUDY ON THE EFFECT OF TAMSULOSIN IN URETERIC STENT RELATED MORBIDITY
} Pitchaibalashanmugham Karrupaiah ${ }^{1}$, Rajaraman Thiagarajan², Periasamy Ponnusamy3, Thiruvarul Palanisamy Venkatachalam
Kamalesh Kumar

1 Professor and HOD, Department of Urology, Government Stanley Medical College.

${ }^{2}$ Professor, Department of Urology, Government Stanley Medical College.

${ }^{3}$ Senior Assistant Professor, Department of Urology, Government Stanley Medical College.

${ }^{4}$ Senior Assistant Professor, Department of Urology, Government Stanley Medical College.

${ }^{5}$ Assistant Professor, Department of Urology, Government Stanley Medical College.

${ }^{6}$ Post Graduate, Department of Urology, Government Stanley Medical College.

${ }^{7}$ Post Graduate, Department of Urology, Government Stanley Medical College.

${ }^{8}$ Post Graduate, Department of Urology, Government Stanley Medical College.

\section{ABSTRACT}

Urolithiasis is a very common problem, and the challenges that it has posed has been instrumental in devising various means to tackle the stone burden. With better access, visualization and stone fragmenting techniques, end urological procedures have become a mainstay in treatment of stone despite the vast evidence supporting nonstented ureteroscopies, worldwide many urologists still prefer to place stents in majority of uncomplicated stone removal procedures in a bid to improve drainage, stone eases. Ureteric stents are associated with a wide spectrum of symptoms thereby producing considerable morbidity ranging from 80 to $98 \%$ and the discomfort caused varies from p Alpha adrenergic receptor like $\alpha 1 \mathrm{~A}$ and $\alpha 1 \mathrm{D}$ have been documented to be distributed the in the lower urinary tract and the distal ureter and the use of alpha adrenergic receptor blockers like Tamsulosin are shown considerable promise in treating the stent related symptoms. Hence this study, was done in an effort to determine the effect of Tamsulosin in improving double-J stent related symptoms and quality of life following ureteral stent placement. This is a prospective study conducted from February 2013 to January 2014 at Government Stanley Hospital. A total of 180 patients were enrolled in this study after following the exclusion and inclusion criteria. Patients were prospectively randomized by random-number chart into two groups. Patients those of whom are prescribed non-selective $\alpha$ adrenergic receptor blockers like Tamsulosin following stenting, seem to benefit significantly because not only did they experience much lesser symptoms and bother, but they also improved over their symptoms with which they presented at admission. This would concur to the explicit influence these group of $\alpha$ adrenergic receptor blockers have over the lower urinary tract and gives them a definite role in treating patients afflicted with stent related morbidity.

\section{KEYWORDS}

Urolithiasis, Stent Symptoms, Tamsulosin.

HOW TO CITE THIS ARTICLE: Pitchaibalashanmugham Karrupaiah, Rajaraman Thiagarajan, Periasamy Ponnusamy, Thiruvarul Palanisamy Venkatachalam, Kamalesh Kumar, Gunaseelan Palanisamy, Kulthe Ramesh Seetharam Bhat, Achi Ranganath Bhaskarapprakash. "A Study on the Effect of Tamsulosin in Ureteric Stent Related Morbidity." Journal of Evolution of Medical and Dental Sciences 2015; Vol. 4, Issue 101, December 17; Page: 16662-16666, DOI: 10.14260/jemds/2015/2487

\section{INTRODUCTION}

Urolithiasis is a very common problem and the challenges that it has posed has been instrumental in devising various means to tackle the stone burden. With better access, visualization and stone fragmenting techniques, end urological procedures have become a mainstay in treatment. Ureteric stents are associated with a wide spectrum of symptoms, thereby producing considerable morbidity ranging from 80 to $98 \%$ and the discomfort caused varies from patient to patient.1,2 Alpha adrenergic receptor like $\alpha 1 \mathrm{~A}$ and $\alpha 1 \mathrm{D}$ have been documented to be distributed the in the lower urinary tract and the distal ureter and the use of alpha adrenergic receptor blockers like Tamsulosin have shown considerable promise in treating the stent related symptoms. $3,4,5$

This study was done in an effort to determine the effect of Tamsulosin in improving double-J stent related symptoms and quality of life following ureteral stent placement. ${ }^{6}$

Financial or Other, Competing Interest: None.

Submission 25-11-2015, Peer Review 26-11-2015,

Acceptance 10-12-2015, Published 17-12-2015.

Corresponding Author:

Dr. Gunaseelan Palansisamy,

NSB $6^{\text {th }}$ Floor,

Govt. Stanley Medical College and Hospital,

Old Jail Road, Royapuram,

Chennai- 600 001, Tamilnadu

E-mail:dr.gunaseelan@gmail.com

DOI:10.14260/jemds/2015/2487

\section{MATERIALS AND METHODS}

This is a prospective study conducted from February 2013 to January 2014 at Government Stanley Hospital. Ethical committee approval was obtained. A total of 180 patients were enrolled in his study after following the exclusion and inclusion criteria.

\section{Inclusion Criteria}

1. Patients undergoing semirigid ureteroscopy with DJ stenting.

2. Only patients with uncomplicated ureteric calculi.

\section{Exclusion Criteria}

Patients with growth in urine culture or having symptomatic urinary tract infection.

1. Patients who may need bilateral stent insertion for acute obstruction/obstructive uropathy.

2. Male patients with history of prostatic enlargement, prostatitis or prostatic cancer related lower urinary tract symptoms.

3. Females with lower urinary tract symptoms related to any form of urinary incontinence, uterine/cervical/vaginal prolapse or obstruction related to malignancy.

4. History of chronic or recent $\alpha$-blocker or analgesic drug use were excluded.

5. Pregnancy.

6. Bleeding disorders. 
7. Patients with concomitant other lower tract pathology like bladder cancer, bladder outlet obstruction with or without stones, urethral stricture.

8. Patients with simultaneous renal calculus.

9. Patients who underwent open surgery for ureteric calculi previously.

\section{STUDY DESIGN}

Patients were prospectively randomized by random-number chart into two groups.

Group A comprised of patients who received Tab. Ciprofloxacin 500mg twice daily and Tab. Paracetamol 500mg thrice daily for three days.

Group B comprised of patients who received Tab Ciprofloxacin 500mg twice daily, Tab. Paracetamol 500mg thrice daily for three days and Tab. Tamsulosin $0.4 \mathrm{mg}$ once daily for two weeks (14 days).

\section{URINARY TRACT SYMPTOM ASSESSMENT}

The International Prostate Symptom Score (IPSS) questionnaire. 7,8 was used to assess patient's symptoms on admission as a baseline before patient underwent the surgery and again reassessed after two weeks when the patient came for stent removal.

The IPSS questionnaire consists of seven questions, four relating to voiding (Obstructive) symptoms and three to storage (Irritative) symptoms. Responses were graded on a five-point rating scale. The maximum scores for voiding and storage symptoms are 20 and 15, respectively; the higher the score, the worse are the symptoms.

\section{QUALITY OF LIFE ASSESSMENT}

Quality of life (QofL) was assessed on admission as a, baseline before patient underwent the surgery and again reassessed after two weeks when the patient came for stent removal using the QofL section of the IPSS questionnaire.

\section{VISUAL ANALOG PAIN SCALE}

Also the pain component is evaluated by the Visual Analog Pain Scale. On admission as a baseline before patient underwent the surgery and again reassessed after two weeks when the patient came for stent removal.

All the scoring is done after adequately explaining about each component of the chart each time.

They were asked to report to the casualty department in case of any emergency. A discharge summary was given with clear instructions and a stent diary was maintained in the department with all details about patient particulars like address, contact phone number and probable date of stent removal and maintained regularly.

Stent removal was done under local anesthesia as an outpatient procedure using $20 \mathrm{Fr} / 30$-degree scope.

\section{METHODOLOGY}

These patients were evaluated by taking a detailed history followed by a complete clinical examination. Relevant past, personal history and clinical data along with co-morbid factors are noted. Routine blood investigations along with renal function test including blood urea and serum creatinine level, urinalysis and urine culture sensitivity were done and recorded. Further evaluation in the form of X-ray KUB, USG abdomen and pelvis, were done both pre-operatively and postoperatively. Based on this data diagnosis was made and planned for ureteroscopy and DJ stenting. Anesthetist fitness was obtained for surgery accordingly. An informed consent and consent for stenting was obtained from the patient after clearly explaining about the procedure and the implications.
Indication for stent placement in each case was noted. Patients are given a questionnaire to assess the baseline symptoms using the IPSS questionnaire along with the quality of life component of the chart as prescribed by AUA guidelines. Also the pain component is evaluated by the Visual Analog Pain Scale ${ }^{\mathrm{TM}}$ followed universally. Scoring is done after adequately explaining about each component of the chart.

Under spinal anesthesia, patient was placed in the lithotomy position with ipsilateral leg lower and straighter to facilitate easy ureteroscope entry. Cystoscopy was done using 20 -Fr sheath 30-degree scope. The entire urethra assessed and bladder visualized for any associated pathology. Both ureteric orifices were visualized and 0.032 -inch guidewire passed into the ipsilateral ureter containing the stone. Then the cystoscope was removed and 8-Fr infant feeding tube was passed into the bladder. 8/9.8-Fr semirigid ureteroscope was passed into the ureter under normal saline irrigation and passed proximally up into the ureter until the calculus is visualized.

Patients with intra-operative findings of difficult ureteroscope entry, ureteric stricture, dense stone impaction, edema and bleeding were excluded from the study. Then using pneumatic lithotripsy stone is fragmented completely. Following this patients underwent DJ stenting with $5-\mathrm{Fr} / 26 \mathrm{~cm}$ one end open silastic DJ stent. Patients who had residual stone fragments that could not be fragmented at all were exclude from the study. Post-operatively patients were explained about the presence of DJ stent, and the need to come for stent removal after 2 weeks (14 days). A post-operative imaging is done to confirm the position of the stent. Then the patients are discharged on the $2^{\text {nd }} / 3^{\text {rd }}$ post-operative day if there is no significant event and are prescribed medicines as per the group they are allotted to based on the random number chart.

\section{STATISTICAL ANALYSIS}

Data were analysed using $\chi 2$ test, Student's ' $\mathrm{t}$ ' test, Independent sample $\mathrm{T}$ test and paired sample $\mathrm{T}$ test.

\section{AGE AND SEX DISTRIBUTION}

The mean age of patients in Group A and was 35.79 with an age range of 10 to 62 years. The mean age of patients in Group B was 36.62 with an age range of 13 to 64 years.

In Group A consisted of 58 men and 32 women, whereas Group B had 54 men and 36 women.

\begin{tabular}{|c|c|c|}
\hline AGE & GROUP A & GROUP B \\
\hline Mean & 35.79 & 36.62 \\
\hline Range & 10 to 62 & 13 to 64 \\
\hline \multicolumn{3}{|c|}{ Table 1: Age Distribution } \\
\hline
\end{tabular}

\begin{tabular}{|c|c|c|}
\hline GENDER & GROUP A & GROUP B \\
\hline Male & 58 & 54 \\
\hline Female & 32 & 36 \\
\hline \multicolumn{3}{|c|}{ Table 2: Sex Distribution } \\
\hline
\end{tabular}

\section{STONE CHARACTERISTICS}

In Group A 25, 12 and 53 patients had upper, mid and lower ureteric calculus respectively. In Group B 24, 10 and 56 patients had lower ureteric calculus respectively.

\begin{tabular}{|c|c|c|c|}
\hline \multirow{3}{*}{$\begin{array}{c}\text { LOCATION OF } \\
\text { CALCULUS }\end{array}$} & GROUP A & GROUP B \\
\cline { 2 - 4 } & Upper ureteric & 25 & 24 \\
\cline { 2 - 4 } & Mid ureteric & 12 & 10 \\
\cline { 2 - 4 } SIDE & Lower ureteric & 53 & 56 \\
\cline { 2 - 4 } & Right & 43 & 48 \\
\hline \multicolumn{2}{|c|}{ Left } & 47 & 42 \\
\hline \multicolumn{2}{|c|}{ Table 3: Stone Characteristics Chart } \\
\hline
\end{tabular}




\begin{tabular}{|c|c|c|c|c|c|}
\hline & \multicolumn{2}{|c|}{ Group A } & \multicolumn{2}{c|}{ Group B } & $\begin{array}{c}\text { P } \\
\text { Value }\end{array}$ \\
\cline { 2 - 5 } & Mean & SD & Mean & SD & 0.431 \\
\hline $\begin{array}{c}\text { Total IPSS } \\
\text { Score }\end{array}$ & 7.68 & 2.18 & 7.91 & 1.77 & 0.298 \\
\hline $\begin{array}{c}\text { Irritative } \\
\text { symptom score }\end{array}$ & 3.32 & 0.99 & 3.48 & 1.01 & 0.672 \\
\hline $\begin{array}{c}\text { Obstructive } \\
\text { symptom score }\end{array}$ & 4.36 & 1.39 & 4.43 & 1.04 & 0.674 \\
\hline $\begin{array}{c}\text { Visual analog } \\
\text { pain scale }\end{array}$ & 4.24 & 1.04 & 4.31 & 1.08 & 0.674 \\
\hline Quality of life & 2.89 & 0.68 & 3.06 & 0.61 & 0.084 \\
\hline \multicolumn{7}{|c|}{ Table 4: Comparison of Both Groups at Baseline } \\
\hline
\end{tabular}

\begin{tabular}{|c|c|c|c|c|c|}
\hline & \multicolumn{2}{|c|}{ Group A } & \multicolumn{2}{c|}{ Group B } & \multirow{2}{*}{ P Value } \\
\cline { 2 - 6 } & Mean & SD & Mean & SD & \\
\hline $\begin{array}{c}\text { Total IPSS } \\
\text { Score }\end{array}$ & 13.37 & 2.13 & 5.12 & 0.67 & $<0.001$ \\
\hline $\begin{array}{c}\text { Irritative } \\
\text { symptom score }\end{array}$ & 8.82 & 1.76 & 2.34 & 0.50 & $<0.001$ \\
\hline $\begin{array}{c}\text { Obstructive } \\
\text { symptom score }\end{array}$ & 4.54 & 0.75 & 2.78 & 0.70 & $<0.001$ \\
\hline $\begin{array}{c}\text { Visual analog } \\
\text { pain scale }\end{array}$ & 5.67 & 0.92 & 3.10 & 0.70 & $<0.001$ \\
\hline Quality of life & 3.43 & 0.81 & 2.08 & 0.74 & $<0.001$ \\
\hline Table 5: Comparison of Both Groups at Stent Removal \\
\hline
\end{tabular}

\begin{tabular}{|c|c|c|c|c|c|}
\hline \multirow{3}{*}{ Variables } & \multicolumn{4}{|c|}{ Group A } & \multirow{3}{*}{$\begin{array}{c}\mathbf{P} \\
\text { Value }\end{array}$} \\
\hline & \multicolumn{2}{|c|}{ Baseline } & \multicolumn{2}{|c|}{$\begin{array}{l}\text { At Stent } \\
\text { Removal }\end{array}$} & \\
\hline & Mean & SD & Mean & SD & \\
\hline $\begin{array}{c}\text { Total IPSS } \\
\text { Score }\end{array}$ & 7.68 & 2.177 & 13.37 & 2.133 & $<0.001$ \\
\hline $\begin{array}{l}\text { Irritative } \\
\text { symptom } \\
\text { score }\end{array}$ & 3.32 & 0.992 & 8.82 & 1.765 & $<0.001$ \\
\hline $\begin{array}{l}\text { Obstructive } \\
\text { symptom } \\
\text { score }\end{array}$ & 4.36 & 1.393 & 4.55 & 0.752 & $<0.135$ \\
\hline $\begin{array}{c}\text { Visual } \\
\text { analog } \\
\text { pain scale }\end{array}$ & 4.24 & 1.042 & 5.67 & 0.924 & $<0.001$ \\
\hline $\begin{array}{l}\text { Quality of } \\
\text { life }\end{array}$ & 2.89 & 0.678 & 3.43 & 0.808 & $<0.001$ \\
\hline \multicolumn{6}{|c|}{ Table 6: Comparison within Group A } \\
\hline
\end{tabular}

\begin{tabular}{|c|c|c|c|c|c|}
\hline & \multicolumn{4}{|c|}{ Group B } & \\
\hline \multirow{2}{*}{ Variables } & \multicolumn{2}{|c|}{ Baseline } & \multicolumn{2}{c|}{$\begin{array}{c}\text { At Stent } \\
\text { Removal }\end{array}$} & $\begin{array}{c}\text { P } \\
\text { Value }\end{array}$ \\
\cline { 2 - 5 } & Mean & SD & Mean & SD & \\
\hline $\begin{array}{c}\text { Total IPSS } \\
\text { Score }\end{array}$ & 7.91 & 1.171 & 5.12 & 0.668 & $<0.001$ \\
\hline $\begin{array}{c}\text { Irritative } \\
\text { symptom } \\
\text { score }\end{array}$ & 3.48 & 1.008 & 2.34 & 0.501 & $<0.001$ \\
\hline $\begin{array}{c}\text { Obstructive } \\
\text { symptom } \\
\text { score }\end{array}$ & 4.43 & 1.039 & 2.78 & 0.700 & $<0.001$ \\
\hline $\begin{array}{c}\text { Visual } \\
\text { analog } \\
\text { pain scale }\end{array}$ & 4.31 & 1.077 & 3.1 & 0.704 & $<0.001$ \\
\hline $\begin{array}{c}\text { Quality of } \\
\text { life }\end{array}$ & 3.06 & 0.606 & 2.07 & 0.738 & $<0.001$ \\
\hline \multicolumn{7}{|c|}{ Table 7: Comparison within Group B } \\
\hline
\end{tabular}

On comparing both the groups A and B based on the symptom scores assessed at baseline the following observations were made. The mean IPSS score of group A was 7.68 (SD 2.18) with an irritative score of 3.32 (SD 0.99) and obstructive score of 4.36 (SD1.39) and in group B the means of IPSS score, irritative score and obstructive symptom score were 7.91 (SD 1.77), 3.48 (SD 1.01) and 4.43 (SD 1.04). The P value of the above three mean's compared between these two groups were 0.431 for IPSS score, 0.298 for irritative score and 0.672 for obstructive score, indicating that there was not much difference between the two groups (Table No. 3).

The mean visual analog pain scores for group A and B were 4.24 (SD1.04) and 4.31 (SD 1.08). The mean of Quality of Life scores were 2.89 (SD 0.68) and 3.06 (SD 0.084) for group $A$ and $B$ respectively. Again they indicate that there was no difference in symptoms and bother between the two groups. So the chosen sample population in both the groups were the same at baseline since the difference between them were not statistically significant.

On comparing both the groups A and B based on the symptom scores assessed at stent removal after 2 weeks (14 days) the following observations were made. The mean IPSS score of group A was 13.37 (SD 2.13) with an irritative score of 8.82 (SD 1.76) and obstructive score of 4.54 (SD 0.75) and in group $B$ the means of IPSS score, irritative score and obstructive symptom score were 5.12 (SD0.67), 2.34 (SD 0.50) and 2.78 (SD 0.70). The P value of the above three mean's compared between these two groups were all $<0.001$ indicating, that the difference between these two groups based on these symptom scores were all statistically significant (Table No. 4).

The mean visual analog pain scores for group A and B were 5.67 (SD0.92) and 3.10 (SD 0.70). The mean of Quality of Life scores were 3.43 (SD 0.81) and 2.08 (SD 0.74) for group A and $\mathrm{B}$, respectively. Again both the above observations indicate that the difference in symptoms and bother between the two groups were statistically significant. Hence, it indicates that patients in group B who received tab. Tamsulosin $0.4 \mathrm{mg}$ for 2 weeks showed lesser quantum of symptoms and benefited as compared to those who did not receive it (group A) and the difference is statistically significant.

In group A at baseline the mean of IPSS score was 7.68 (SD2.177), irritative score was 3.32 (SD 0.992), obstructive score was 4.36 (SD 1.393), visual analog scale was 4.24 (SD 1.042) and the quality of life score was 2.89 (SD0.678), but at stent removal the mean these scores were 13.37 (SD 2.133) for IPSS, 8.82 (SD 1.765) for irritative score, 4.55 (SD 0.752) for obstructive score, 5.67 (SD 0.924) for visual analog scale and 3.43 (SD 0.808) for quality of life score (Table No. 4).

These $P$ values of the corresponding means for the variables like IPSS score, irritative score, visual analog pain scale and quality of life scale were statistically significant $(<0.001)$ indicating that the among patients who underwent stenting and did not receive tab. Tamsulosin $0.4 \mathrm{mg}$ the symptom scores at baseline had worsened except for the obstructive score whose $\mathrm{P}$ value was 0.135 and was not statistically significant.

In group B at baseline the mean of IPSS score was 7.91 (SD1.771), irritative score was 3.48 (SD 1.008), obstructive score was 4.43 (SD 1.039), visual analog scale was 4.31 (SD1.077) and the quality of life score was 3.06 (SD 0.606), but at stent removal the mean of these scores were 5.12 (SD 0.668) for IPSS, 2.34 (SD 0.501) for irritative score, 2.78 (SD 0.700) for obstructive score, 3.1 (SD 0.704) for visual analog scale and 2.07 (SD 0.738) for quality of life score (Table No. 5).

The $P$ values of the corresponding means for the variables like IPSS score, irritative score, obstructive score, visual analog pain scale and quality of life scale were all statistically significant $(<0.001)$ indicating that among 
patients who underwent stenting and received tab. Tamsulosin $0.4 \mathrm{mg}$ the symptom scores at baseline did not show worsening of symptoms after stenting at 2 weeks and also showed considerable improvement in symptom scores over the baseline.

\section{DISCUSSION}

In a study conducted by Auge and colleagues, among community and practicing urologists from centers all over the world they reported that $98 \%$ of them would perform ureteroscopic stone surgery as a routine. Among these, twothirds of them would place a stent more than half $(>50 \%)$ of the time and $13 \%$ would always prefer to place a postoperative stent, even though stent related symptoms and morbidity were a significant problem faced by patients (98\%).

Despite advances and refinements in stent design and material, extensive use of ureteral stenting following endourologic surgeries, is associated with considerable morbidities comprising of urinary symptoms, pain and a definite impact on quality of life of the patient. In our study among the group A patients, the data and the subsequent observations suggest that stenting has produced significant $(\mathrm{P}<0.001)$ symptoms related to it. Joshi et al and Miyako et al. have shown that stent related symptoms occur in about more than $80 \%$ of the patients and is a common problem faced by the patient and dealt routinely by the urologist.

The cause of stent-related symptoms and the mechanisms involved are not fully understood and it is contemplated that the involuntary contraction of the bladder secondary to irritation of the trigone contributes to the bothersome urinary symptoms. In addition, increased resistance to bladder outlet and pressure generated during micturition lead to reflux of urine.

Alpha-blockers reduce flank pain by causing a decrease in the muscle tone of the ureter, trigone of the bladder and prostatic urethra by means of blocking the $\alpha$-adrenergic receptors and thereby decreasing the bladder outlet resistance and the pressure developed during micturition. In our study it is observed that patients who received Tab. Tamsulosin $0.4 \mathrm{mg}$ following stenting showed definitely lesser symptoms overall and also demonstrated a significant reduction in their baseline bother symptoms. This indicates to the comprehensive effect of tamsulosin in lower urinary tract symptoms, which is due to its action on $\alpha 1 \mathrm{~A}$ and $\alpha 1 \mathrm{D}$ receptors distributed across the lower urinary tract.

Considering and study and two meta-analyses that were been recently published, it seems that $\alpha$-blockers can effectively relieve stent-related symptoms. The patients receiving Tamsulosin experienced significant reductions in the total IPSS, irritative subscore, flank and voiding pains and QoL compared with those that did not receive it.

Although, all patients had correct stent placement at discharge, one patient in the tamsulosin group and three patients in the group that did not receive it complained of severe pain and the stents were removed much earlier in all the 4 patients ( 3 in group A and 1 in group B) and were excluded from the study. Also 5 patients developed hematuria during the course of the study in the post-operative period and were excluded from the study.

So stent related morbidity a common problem faced by every urologist, which puts them through a dilemma, in which case every scenario has to weighed against the pros and cons. Stenting per se causes unnecessary increase in cost in the form of extra procedure to remove it and the cost towards the stent and the cost involved in treating the complications and the lingering odd risk of forgotten stent which might present at a later date with a variety of problems like encrustation, renal calculi ,infection ,sepsis and the difficult scenario of renal failure. At same time in cases where stenting is done for genuine causes the related symptoms can be treated effectively by $\alpha$-blockers like Tamsulosin.

\section{LIMITATIONS OF THE STUDY}

1. We applied stents of same size and length for all patients; however, some studies have shown that the stent length is directly proportional with stent-related symptoms, and some studies have shown evidence to the contrary. Given this point, we used same length $(26 \mathrm{~cm} / 5-\mathrm{Fr})$ stents for all the patients.

2. We used the IPSS scoring for evaluation of urinary symptoms, but Joshi et al. have developed a specific tool for assessing stent-related symptoms which is named "Ureteric Stent Symptoms Questionnaire" (USSQ). Although, it has been previously implemented, we could not apply it due to complexity of the variables involved and its validity and reliability which were not confirmed till date.

\section{CONCLUSION}

Stenting the ureters following endourologic procedures though being done routinely is not without its problems. It is most commonly associated with considerable symptoms, like irritative voiding symptoms, pain and bother so much, that it affects the quality of life of the patient significantly.

The quantum of pain , irritative symptoms and afflicted quality of life which the patient is put through should be borne in mind and carefully weighed against the benefits they might provide and the decision should be individualized in each patient every time.

- In such cases where stenting is being done, the patient should be given the benefit of having the stent and at the same time his symptoms should be alleviated by the judicial use of tablet tamsulosin $0.4 \mathrm{mg}$ once daily for 14 days.

- Stent related morbidity is an entity in itself and the influence of $\alpha$ adrenergic receptor blockers like Tamsulosin over the irritative symptoms is significant due to the distribution of the $\alpha 1 \mathrm{~A}$ and $\alpha 1 \mathrm{D}$ in the lower tract of the urinary system.

- $\quad$ Pain produced by stent may range from flank pain to suprapubic pain to dysuria and the occasional nonspecific lower abdominal pain, which affects the quality of life of the patient significantly. The routine use of nonsteroidal anti-inflammatory drugs like paracetamol do not seem have much influence over the lower urinary tract pain and associated symptoms.

- Definitely, patients those of whom are prescribed non selective $\alpha$ adrenergic receptor blockers like Tamsulosin, following stenting seem to benefit significantly because not only did they experience much lesser symptoms and bother, but they also improved over their symptoms with which they presented at admission. This would concur to the explicit influence these group of $\alpha$ adrenergic receptor blockers have over the lower urinary tract and gives them a definite role in treating patients afflicted with stent related morbidity.

\section{BIBLIOGRAPHY}

1. Byrne RR, Auge BK, Kourambas J, et al. Routine ureteral stenting is not necessary after ureteroscopy and ureteropyeloscopy: a randomized trial. J Endourol 2002;16:9-13.

2. Joshi HB, Okeke A, Newns N, et al. Characterization of urinary symptoms in patients with ureteral stents. Urology 2002;59:511-9.

3. Andersson KE: Pharmacology of lower urinary tract smooth muscle and penile erectile tissues. Pharmacol Review 1993; 45:253-308. 
4. Tamsulosin treatment of 19,365 patients with lower urinary tract symptoms: does comorbidity alter tolerability? J Urol 1998; 160:784-791.

5. Schulman CC, Lock TM, Buzelin JM, et al.: Long-term use of tamsulosin to treat lower urinary tract symptoms/benign prostatic hyperplasia. J Urol 2001; 166:1358-1363.

6. Deliveliotis C, Chrisofos M, Gougousis E, et al.: Is there a role for alpha1-blockers in treating double-J stentrelated symptoms? Urology 2006; 67:35-39.
7. Hsiao SM1, Lin HH, Kuo HC: International prostate symptom score for assessing lower urinary tract dysfunction in women. Int Urogynecol J. 2013 Feb;24(2):263-7. doi: 10.1007/s 00192-012-1818-8. Epub 2012 May 16.

8. Cam K1, Akman Y, Cicekci B, et al. Mode of administration of international prostate symptom score in patients with lower urinary tract symptoms: physician vs self. Prostate Cancer Prostatic Dis. 2004;7(1):41-4. 